\title{
ADUBAÇÃO FOLIAR DO ALGODOEIRO (Gossypium hirsutum, L., var. I.A.C.12), COM NITROGÊNIO, FÓSFORO E POTÁSSIO AVALIADA PELA PRODUÇÃO E DIAGNOSE FOLIAR *
}

\author{
Julio P. LaCa Buendia
}

A. M. Louis NePtune

\begin{abstract}
Aplicações de adubos por via foliar no algodoeiro tem sido feitas em outros países; porém, no Brasil, tal prática encontra-se no inicio.

Com o presente trabalho, foi estudado o efeito da adubação foliar nos aumentos de produção e foi estabelecido correlacões entre a produção e as concentrações de nitrogênio, fósforo e potássio, nos pecíolos das fôlhas de ramos produtivos e não produtivos.
\end{abstract}

\section{INTRODUÇÃO}

$\mathrm{O}$ algodoeiro era cultivado e industrializado em muitos lugares da América do Sul e Central quando da descoberta do Novo Mundo. No litoral do Perú, existiu uma antiga e avançada indústria textil. Os tecidos encontrados intactos nas tumbas cavadas naquele solo de sértico, comprovaram o fato. Nada comparável tem sido mencionado nos outros países da América, embora saiba-se pelos documentos históricos que o algodão era utilizado para fazer tecidos (HUTCHISON, 1962).

O algodão é a fibra textil mais importante, seja considerando o volume da produção, o valor monetário da mesma ou a multipilicidade de produtos que dele se originam. No Brasil, desde que o algodão tornou-se uma cultura economica, sempre figurou no grupo vanguardeiro das atividades que trazem divisas para o país. O algodoeiro é a planta de aproveitamento mais completo e a que oferece a mais variada gama de produtos de utilidade universal.

* Entregue para publicação em 20/1/1971. Parte da Tese apresentada à Escola Superior de Agronomia "Luiz de Queiroz", para a obtenção do Título de Magister Scientiae, pelo primeiro autor.

$\because$ Universidade de Lambayeque - Perú

*:* Departamento de solos e Geologia - ESALQ - USP

***** Agradecimentos são devidos ao Dr. ROLAND VENCOVSKY, Docente-Livre do Departamento de Genética pela colaboração na análise estatística, aos Srs. Vinicius Ferraz e Valentin Bombo Filho pelos servicos prestados. 
É produzido por quatro espécies de genero Gossypium. Duas delas: G. herbaceum e G. arboreum, são originárias do Velho Mundo e as duas outras G. barbadense e G. hirsutum, do Novo Mundo.

No Brasil desde que o algodoeiro começou a tomar aspecto de cultura economica, sempre encontrou-se em situação relativamente privilegiada. Segundo o anuário estatístico do Brasil 1968, a extensão de área ocupada é a terceira no País em importancia, superada pelo milho e arroz. A exportação desta malvácea ocupa o segundo lugar superada somente pelo café e neste ano espera-se novo recorde (VANNI 1969).

A adubação é uma das práticas agrícolas mais importantes na cultura do algodoeiro. Aplicações de fertilizantes por via foliar no algodoeiro tem sido feitas em outros países, porém, no Brasil tal prática acha-se no início. Nos países de agricultura mais adiantada, já tem sido feitas pesquisas, pela possibilidade de economicamente, fornecer elementos nutritivos pelas folhas. Dada a obrigatoriedade do uso na cultura algodoeira, de um esquema definido de controle de pragas, que inclui até o florescimento pelo menos três pulverizações, oferece-se, assim, oportunidade de conjugar as duas práticas, adubação e controle de pragas em uma só aplicação. O Instituto Agronomico de Campinas-Secção de Algodão, no Brasil, é um dos precursores no assunto, pois encontra-se iniciando experiencias para saber as quantidades máximas de adubos nitrogenados, assim como as fontes de maior tolerancia para a planta (FUZATTO, 1965).

Os trabalhos pioneiros de GRIS, 1844; BOHN, 1877; MAYER, 1874 ; HILTNER, 1909, citados por HALLIDAY, 1961, demonstraram que as plantas são capazes de absorver nutrientes pelas folhas. Nos últimos anos, intensificaram-se os estudos sobre pulverização foliar de nutrientes em quase todas as culturas, BOYNTON, 1954; HALLIDAY, 1961; WITTWER, 1964 ; FRANKE, 1967.

DURAN, 1960, na Colombia, trabalhou com concentrações de uréia para aplicação foliar de $1 \%, 3 \%, 5 \%$ e $10 \%$. Os melhores resultados foram obtidos quando a aplicação foi de $200 \mathrm{~kg} / \mathrm{Ha}$ de nitrogênio ao solo e quando a mesma quantidade deste elemento foi subministrado por aspersão foliar de uréia a 3\%. As aplicações de uréia de 5 a $10 \%$ produziram queimaduras nas folhas.

GALIANO, 1961, no Perú, conclui que se pode aplicar nas Folhas $30 \mathrm{~kg} / \mathrm{Ha}$ de uréia, desde que a concentração da pulverização não exceda $2,4 \%$. Verificou-se que altas concentrações causam queima nas fôlhas e que as aplicações não podem ser feitas durante períodos intensos de insolação, ou em dias muitos secos.

Em outro trabalho (ANONIMO, 1962), adubos nitrogenados foram aplicados nas folhas no período de frutificação. Os resultados indi- 
caram que a aplicação de soluções de uréia e nitrato de amonio correspondente a uma concentração de $3 \%$ de nitrogenio na dose 5,5 $\mathrm{kg} / \mathrm{Ha}$, provocaram danos sensíveis nas folhas do algodoeiro. Porém, a mesma solução de uréia correspondente a uma concentração de $3 \%$ de nitrogenio pareciam não prejudicar as folhas de modo que apreciável quando aplicadas frequientemente, porém reduziam os rendimentos onde o solo tinha alto teor de nitrogenio utilizável.

JONES et al. 1962, nos E.U.A., aplicaram uréia em pulvierização foliar no algodoeiro, no período da frutificação. Estes autores acham:

a) que esta prática não é recomendável, embora admitam que uma deficiencia moderada de nitrogenio possa ser corrigida por aspersão foliar;

b) que uma solução de uréia, mesmo com uma concentração de $3 \%$ de nitrogenio, diminui a produção quando existe uma quantidade adequada de nitrogenio disponível no solo;

c) que o biureto, em quantidade comumente encontrada na uréia, não era tóxico ao algodoeiro, quando era aplicada uma solução de uréia a $6,7 \%$.

BRAND e RICHEZ, 1963, fizeram 3 pulverizações com $14 \mathrm{~kg}$ de uréia em 100 litros de água na época da floração, com 14 dias de intervalo entre as mesmas. Obtiveram aumento de produção significativo em relação a testemunha e ao tratamento em que foram colocados nitrogenio, fósforo e enxofre no sulco do plantio.

VERNA e SAHMI, 1963, na India, verificaram que a aplicação de $9 \mathrm{~kg}$ de nitrogenio ao solo, no momento do plantio, aumentou o rendimento em $114 \mathrm{~kg}$ de nitrogenio por aspersão foliar, no momento da formação das maçãs, aumentou o rendimento em $74 \mathrm{~kg}$.

DARGAN e SINGH, 1964, na India, verificaram, em solos deficientes de nitrogenio com valores de $\mathrm{pH} \mathrm{8,} \mathrm{0-8,5} \mathrm{de} \mathrm{textura} \mathrm{Barro-arenosa}$ e Arenosa-barrenta, que o nitrogenio aumentou significativamente o rendimento. Não houve efeito do fósforo e os métodos de aplicação tiveram um efeito similar sobre o rendimento. Com aplicações foliares e doses maiores do que $10-20 \mathrm{~kg} / \mathrm{Ha}$ de nitrogenio, produziram-se deformações nas folhas.

DEBRICAN e THIERRY, 1966, na Estação Experimental de Haute-Volta, na África, conduziram alguns ensaios com a finalidade de verificar se um complemento do nitrogenio era útil no momento da floração do algodoeiro, principalmente em solos arenosos. Aplicaram $750 \mathrm{~g}$ de uréia/7 litros de água, junto com inseticida, dando $15 \mathrm{~kg}$ de uréia/Ha/ tratamento. A adubação fundamental foi de $100 \mathrm{~kg} / \mathrm{Ha}$ de sulfato de amônio e de $150 \mathrm{~kg} / \mathrm{Ha}$ de superfosfato triplo. 
SEMENT, 1967, na Estação Experimental de Kogoni, na África, comparou a eficiencia da uréia aplicada totalmente ao solo na quantidade de $250 \mathrm{~kg} / \mathrm{Ha}$ e parte ao solo $(210 \mathrm{~kg} / \mathrm{Ha})$ e parte em aspersão foliar $(40 \mathrm{~kg} / \mathrm{Ha})$. Não encontrou nenhuma diferença entre os dois modos de aplicação. Êste autor recomenda a aplicação ao solo de toda a uréia aos 30-35 dias após a semeadura.

CORRE e THIERRY, 1968, na Estação Experimental de HauteVolta, na África, fizeram uma aplicação suplementar de $45 \mathrm{~kg} / \mathrm{Ha}$ de uréia no momento da floração, juntamente com inseticida. Não houve nenhum efeito significativo quando as parcelas receberam uma adubação de $100 \mathrm{~kg}$ de sulfato de amônio e de $150 \mathrm{~kg}$ de superfosfato triplo ou a metade destas doses. Por outro lado, quando a uréia, a doses iguais foi aplicada ao solo ou nas folhas, não houve aumento significativo na produção.

MATHUR et al., 1968, na Índia, realizaram estudos comparativos da aplicação de uréia ao solo e na folha em vários níveis. Estes pesquisadores encontraram diferença significativa entre os dois modos de aplicação, resultando maior altura da planta e maior número de maçãs por planta, com a pulverização foliar.

MACHADO, 1968, na Secção de algodão do Instituto Agronômico de Campinas, chegou a conclusão de que a uréia é a única que apresenta possibilidade de pulverização foliar no algodoeiro, após comparação entre várias fontes nitrogenadas. O fósforo ocorre nas plantas em quantidades bem menores que as do nitrogenio e potássio.

$\mathrm{O}$ fósforo aplicado às folhas é absorvido muito rapidamente e imediatamente metabolizado. O composto que penetra com maior velocidade é o fosfato diamônico, que é também o composto que as fôlhas absorvem em maiores quantidades (BOYNTON, 1954).

BURKALOV, 1954-1956, em ensaios feitos em Plavdiv, na URSS., estudou a influencia do fósforo e verificou uma formação e maturação precoces de um grande número de maçãs, assim como um melhoramento da qualidade do algodão em caroço. Uma solução de superfosfato aumentou o rendimento de 2 a $9 \%$ sendo maior rendimento onde houve combinação da aplicação ao solo e à folha.

MACHIAVELLO e ESTRADA, 1962, no Perú, aplicaram adubos fosfatados na época da floração, usando fosfato monopotássico e o fosfato bicálcio, contendo $24 \%$ de $\mathrm{P}_{2} \mathrm{O}_{5}$ nas doses de 50,30 e 20 $\mathrm{kg} / \mathrm{Ha}$ de $\mathrm{P}_{2} \mathrm{O}_{5}$. Nas tres parcelas o rendimento aumentou pela adição destas doses e a maturação das maçãs foi mais precoce em relação à testemunha.

LANCASTER e SAVATLI, 1965, nos E.U.A., verificaram que quando existe a deficiencia do fósforo, aplicações deste nutriente 
com intervalo freqüente durante o período de frutificação provocaram aumento de rendimento, o qual foi maior a aplicação ao solo. Os autores constataram que soluções contendo 1,5\% de fósforo causaram alguns danos às folhas .

BODADE e MADARIKAR, 1965, na India, verificaram que aplicações ao solo de nitrogenio na dose de $22,5 \mathrm{~kg} / \mathrm{Ha}$ ou do nitrogenio mais fósforo $\left(\mathrm{P}_{2} \mathrm{O}_{5}\right)$ na dose $11,25 \mathrm{~kg} / \mathrm{Ha}$ cada uma, foram mais eficientes e econômicas que a aspersão foliar ao aumento de rendimento do algodoeiro.

Nos E.U.A., TOOMEY, 1967, aplicou fósforo juntamente com inseticida sobre as folhas do algodoeiro cultivado em terra arenosa. Os resultados obtidos pelo autor mostraram que houve maior fixação dos botões florais durante a sêca, maturação mais precoce dos frutos e maior produção do que o tratamento testemunha.

Quanto ao potássio, existem poucos trabalhos sobre a utilização deste nutriente por pulverização foliar no algodoeiro, para outras culturas como no caso do cafeeiro, o nitrato e o cloreto de potássio foram absorvidos com a mesma intensidade que o sulfato, havendo no entanto, uma ligeira predominancia sobre os demais, (NEPTUNE et al., 1961). Em macieira, (BURREL et al., 1942; BURREL e BOYNTON, 1943), citados por BOYNTON, 1954, corrigiram uma deficiencia de potássio. fazendo-se 5 a 6 pulverizações de sulfato de potássio a $1 \%$, porém como resultados destas, produziu-se certa injúria nas folhas.

HANDI et al., 1963, no Egito, fizeram aplicações foliares de nitrogenio, nitrogenio mais fósforo e nitrogenio, fósforo e potássio, num solo limo-argiloso, pH 8,00. Obtiveram o maior aumento com aplicação de NPK, seguido da aplicação de nitrogenio e de nitrogenio mais fósforo. Constataram que a pulverização foliar do fósforo acusou maior rendimento quando comparada com a aplicação ao solo.

MACHADO, 1969, no Brasil, relata resultados de tres ensaios instalados em terra roxa-misturada, para estudar a eficiencia da adubação foliar completa do algodoeiro. Fertilin, adubo mixto comercial, distribuído por "Fertilin, Fertilizantes e Inseticidas Ltda.", foi utilizado em 6 pulverizações efetuadas nos 3 primeiros meses do ciclo das plantas. A produção final do algodão em caroço, vista em conjunto para os tres ensaios, evidenciou o efeito único da aplicação do adubo ao solo. Apenas no último ensaio, constatou-se um certo aumento de produção com adubação foliar.

Por outro lado a análise dos tecidos vegetais - como a análise de solos - converteu-se em um meio conveniente, utilizado por pes- 
quisadores e agricultores, para conhecer as necessidades nutricionais de uma cultura utilizando a própria planta como indicador.

O grande mérito foi de LAGATU \& MAUME, 1962, de haver fixado desde 1924 as bases do que êles chamaram de "Diagnostic Foliaire".

A análise foliar do algodoeiro tem sido pouco explorada. Entre os problemas a serem resolvidos, é importante a escolha da parte da planta que se deve utilizar para a amostragem, o estágio de desenvolvimento da planta apropriada para a amostragem, a forma química do elemento que se deve analisar, além de uma interpretação tão correta quanto possível dos resultados.

JOHAM, 1951, após experimentar várias partes da planta do algodoeiro, encontrou que os pecíolos do caule principal tomados do terceiro e quarto nó, a partir do ápice, refletem o nível de 5 nutrientes no substrato. Mais recentemente, um grande número de publicações menciona a escolha do pecíolo (COWAN et al., 1962; MACKENZIE et al., 1963; PAGE et al., 1963a e 1963b e HARDY, 1965).

No Brasil, MELLO, 1958, estudou a possibilidade da aplicação do método da diagnose foliar no algodoeiro baseando-se na recomendação de PREVOT e OLLAGNIER (1956). Êste autor, analisou o limbo das fôlhas nascidas de ramos produtivos e não produtivos em duas épocas de amostragem: a primeira na época do florescimento e uma segunda por ocasião do apreciamento das primeiras maçãs.

Visto que as pesquisas feitas, até o momento, no Brasil, sôbre a adubação foliar do algodoeiro, diagnose foliar, estão no comêço, resolvemos conduzir êste trabalho, tendo em mente os seguintes objetivos : dução.

1) Avaliar o efeito desta adubação foliar nos aumentos de pro-

2) Avaliar o efeito da adubação foliar pela diagnose foliar, estabelecendo-se correlações entre a produção e as concentrações de nitrogênio, fósforo e potássio, nos pecíolos das fôlhas de ramos produtivos e não produtivos.

$\mathrm{O}$ presente experimento foi instalado em um campo experimental do Departamento de Solos e Geologia, da Escola Superior de Agricultura "Luiz de Queiroz" (ESALQ), a qual situa-se na zona fisiográfica de Piracicaba, tendo como coordenadas geográficas, latitude de $22^{\circ} 42^{\prime} 30^{\prime \prime} \mathrm{S}$. e longitude $47^{\circ} 38^{\prime} 00^{\prime \prime}$ W., com altitude de $580 \mathrm{~m}$ sôbre o nível do mar (CERVELLINI et al., 1968).

O clima do município de Piracicaba é do tipo mesotérmico, Cwa, sistema Kopen, isto é, subtropical úmido com estiagem no inverno; 
as chuvas do mês mais sêco não atingem a $30 \mathrm{~mm}$, e a precipitação pluviométrica (total anual) é de $1254,5 \mathrm{~mm}$; a temperatura média mensal é de $20,8^{\circ} \mathrm{C}$, e a temperatura máxima (média mensal) de $28^{\circ} \mathrm{C}$; sendo a temperatura mínima (média mensal) de $14,7^{\circ} \mathrm{C}$; a umidade relativa média é de 69\%, e as horas de insolação (média) de 203,4 horas (CERVELLINI et al., 1968).

\section{MATERIAL E MÉTODOS}

SOLO - O estudo do solo onde foi instalado o experimento foi feito pelo Centro de Estudo de Solos da ESALQ. Universidade de São Paulo (USP). É classificado com Latosol, recebendo a denominação de terra roxa estruturada, série Luiz de Queiroz que representa $6,1 \%$ da área do município de Piracicaba e $24,4 \%$ na área do grande grupo latosólico (RANZANI et al., 1966).

A variedade utilizada foi I.A.C. (Gossypium hirsutum, L.) originada do cruzamento entre Delfos 1418 x Stoniville 1709. É uma variedade cultivada em todo o Estado de São Paulo, exceto nas regiões onde aparece a "Murcha" (Fusarium vasinfectum) (COSTA et al., 1965).

Delineamento experimental - Foi o desenho experimental de Blocos ao acaso, partes dos tratamentos foram organizados de maneira a se enquadrar num factorial $4 \times 3$, sendo 4 o número de níveis e 3 o número dos adubos. Além dêstes 12 tratamentos, foram incluidos êstes: $\mathrm{N}_{0} \mathrm{P}_{0} \mathrm{~K}_{0}, \mathrm{~N}_{1} \mathrm{P}_{3} \mathrm{~K}_{3}, \mathrm{~N}_{3} \mathrm{P}_{1} \mathrm{~K}_{3}, \mathrm{~N}_{3} \mathrm{P}_{3} \mathrm{~K}_{12}, \mathrm{~N}_{3} \mathrm{P}_{3}$. Porém cada Bloco tinha 21 varcelas, porque os tratamentos $\mathrm{N}_{0} \mathrm{P}_{0} \mathrm{~K}_{0}$ e $\mathrm{N}_{3} \mathrm{P}_{3} \mathrm{~K}_{3}$ foram repetidas 3 vêzes dentro de cada Bloco, para aumentar a precisão das respectivas médias.

O seguinte esquema permite visualizar melhor êstes tratamentos.

$$
\begin{aligned}
& \mathrm{N}_{0} \mathrm{P}_{0} \mathrm{~K}_{0} \\
& \mathrm{~N}_{1} \mathrm{P}_{3} \mathrm{~K}_{3} \\
& \mathrm{~N}_{0} \mathrm{P}_{0} \mathrm{~K}_{\text {) }} \\
& \mathrm{N}_{3} \mathrm{P}_{3}, \mathrm{~K}_{33} \\
& \mathrm{~N}_{3} \mathrm{P}_{1} \mathrm{~K}_{3} \\
& \mathrm{~N}_{3} \mathrm{P}_{: ;} \mathrm{K}_{3} \\
& \mathrm{~N}_{0} \mathrm{P}_{0} \mathrm{~K}_{0} \\
& \left(A_{1}\right)\left\{\begin{array}{l}
\mathrm{P}_{3} \mathrm{~K}_{3}+\mathrm{N}_{0} * \\
\mathrm{P}_{3} \mathrm{~K}_{3}+\mathrm{N}_{1} * \\
\mathrm{P}_{3} \mathrm{~K}_{3}+\mathrm{N}_{2} * \\
\mathrm{P}_{3} \mathrm{~K}_{3}+\mathrm{N}_{3} *
\end{array}\right. \\
& \left(A_{2}\right)\left\{\begin{array}{l}
\mathrm{N}_{3} \mathrm{~K}_{3}+\mathrm{P}_{0} * \\
\mathrm{~N}_{3} \mathrm{~K}_{3}+\mathrm{P}_{1} * \\
\mathrm{~N}_{3} \mathrm{~K}_{3}+\mathrm{P}_{2} * \\
\mathrm{~N}_{3} \mathrm{~K}_{3}+\mathrm{P}_{3} *
\end{array}\right. \\
& \mathrm{N}_{3} \mathrm{P}_{3} \mathrm{~K}_{1} \\
& \mathrm{~N}_{3} \mathrm{P}_{3} \mathrm{~K}_{3}
\end{aligned}
$$

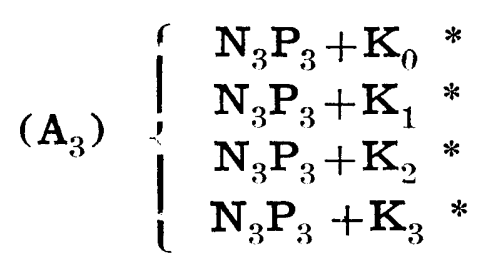

* Os asteristicos indicam que o elemento foi aplicado nas folhas.

A área total da parcela foi de $15,00 \mathrm{~m}^{2}$, sendo a área útil de 7,60 $\mathrm{m}^{2}$. A área de cada bloco foi de $315,00 \mathrm{~m}^{2}$. 


\section{Preparo do solo e demarcação do experimento}

Foram realizadas duas arações profundas com arados de discos seguidas de duas gradações no dia da semeadura. A seguir, foram delimitadas a área de cada bloco e as respectivas parcelas.

\section{Análise química do solo}

De cada bloco foram colhidas amostras compostas de solo para determinações analíticas (CATANI et al., 1955).

Nas amostras compostas foram determinados: a) o valor $\mathrm{pH}$, no potenciômetro Beckman, utilizando-se a relação solo: água, igual a $1: 2,5$; b) matéria orgânica, através do método de WALKLEY \& BLACK, descrito em MALAVOLTA e COURY, 1954; c) Nitrogênio total, pelo método de Kjeldahl, descrito por JACKSON, 1958; d) Fósforo solúvel e Potássio trocável, de acôrdo com os métodos descritos por CATANI et al., 1955; e) Cálcio e Magnésio trocáveis, foram determinados pelo método de EDTA descrito por GLORIA et al., 1965. 1955.

As interpretações dos teores foram feitas segundo CATANI et al.,

\section{Plantio}

Foi efetuado no dia 13 de novembro de 1968. As sementes foram colocadas seguidas no sulco, deixando-se cair 30-40 sementes por metro de sulco, que corresponde a um gasto de 35 a $45 \mathrm{~kg} / \mathrm{Ha}$ de sementes. Adotamos o espaçamento de $1,00 \times 0,20 \mathrm{~m}$.

\section{Adubação}

Tanto na adubação ao solo, como na adubação foliar, foi utilizado como fonte de nitrogênio, a uréia (46\% N'), como fonte de fósforo, o superfosfato concentrado $\left(45 \% \mathrm{P}_{2} 0_{5}\right)$ e como fonte de potássio, o cloreto de potássio $\left(60 \% \mathrm{~K}_{2} 0\right)$.

\section{No solo}

A adubação foi feita manualmente, no momento da semeadura, tratou-se sempre de colocar o adubo de $2-3 \mathrm{~cm}$ ao lado e de $4-5 \mathrm{~cm}$ abaixo das sementes.

As quantidades dos adubos a serem aplicados encontram-se na Tabela I.

O nitrogênio no nível 1 foi aplicado $1 / 2$ no plantio e $1 / 2$ após o desbaste e no nível $2,1 / 3$ no plantio e $2 / 3$ após o desbaste. As quantidades de fósforo e de potássio foram aplicadas no plantio. 
TABELA I - Quantidades dos adubos aplicados no solo.

\begin{tabular}{lcrrr}
\hline Adubo & Nível & $\begin{array}{c}\text { Elemento } \\
\mathrm{kg} / \mathrm{Ha}\end{array}$ & $\begin{array}{r}\text { Adubo } \\
\mathrm{g} / \text { parcela }\end{array}$ & $\begin{array}{r}\text { Adubo } \\
\mathrm{g} / \text { sulco }\end{array}$ \\
\hline & 0 & 0,00 & 0,00 & 0,00 \\
Uréia & 1 & 20,00 & 65,22 & 16,30 \\
& 3 & 60,00 & 195,66 & 48,90 \\
\hline Superfosfato & 0 & 0,00 & 0,00 & 0,00 \\
Concentrado & 1 & 20,00 & 66,66 & 16,66 \\
& 3 & 60,00 & 199,99 & 49,99 \\
\hline $\begin{array}{l}\text { Cloreto } \\
\text { de }\end{array}$ & 0 & 0,00 & 0,00 & 0,00 \\
Potássio & 1 & 20,00 & 49,99 & 12,49 \\
& 3 & 60,00 & 149,94 & 37,48 \\
\hline
\end{tabular}

\section{Por pulverização foliar}

As quantidades dos adubos e o número de pulverizações foliares encontram-se na Tabela II. No cálculo das quantidades de superfosfato concentrado, o teor de $\mathrm{P}_{2} \mathrm{O}_{\overline{5}}$ considerados foi de $37,5 \%$, como será explicado em 3.9.2.2.

Nas aplicações dos adubos, por pulverização foliar, utilizando-se em cada aplicação $1 / 3$ da dose total, iniciaram-se aos 51 dias após a germinação, no dia $10 / 1 / 69$, quando os botões florais estavam em formação, porém esta aplicação foi considerada perdida porque choveu após a mesma. Repetiu-se aos 55 dias após a germinação, no dia 14/1/69. A segunda aplicação foi realizada aos 76 dias após a germinação, no dia $4 / 2 / 69$, em plena floração. A terceira aplicação foi realizada aos 97 dias após a germinação, no dia $25 / 2 / 69$, porém foi perdida porque choveu após a mesma. Esta aplicação foi feita novamente aos 108 dias após a germinação, no dia $7 / 3 / 69$, quando maior parte das plantas mostravam as maçãs em pleno desenvolvimento.

\section{Equipamento usado}

Utilizou-se um pulverizador de ar comprimido, marca "GUARANY" cujo depósito tem capacidade para 5 litros. Foram feitas as seguintes modificações: a) adaptou-se um manômetro marca "RECORD", de 0,60 1b/pol ${ }^{2}$ com válvula reguladora à saída do depósito para o cano pulverizador; b) para fornecer o ar, era utilizado um compressor de ar, portátil, marca "KEYSTONE", com capacidade de $0-150 \mathrm{1b} / \mathrm{pol}^{2}$, o qual era adotado de uma válvula reguladora e 
de um manômetro para controlar a saída do ar; c) o bico utilizado foi o "TEEJET" 8002, o qual era mantido a uma distância de $50 \mathrm{~cm}$ da planta, por meio de uma varinha de ferro soldada, perto do bico, ao cano do pulverizador.

A pressão de saída para o bico pulverizador era de $30 \mathrm{1b} / \mathrm{pol}^{2}$.

As características do equipamento aqui mencionadas foram estabelecidas em base a experimentos prévios de laboratório e de campo.

\section{Preparo das soluções usadas}

Os adubos (uréia e cloreto de potássio) foram dissolvidos nas quantidades correspondentes de água destilada, em $1600 \mathrm{ml}$ quando da primeira aplicação e em $1800 \mathrm{ml}$ quando da segunda e terceira aplicações.

TABELA III - Quantidades de adubos aplicados por pulverização foliar

\begin{tabular}{|c|c|c|c|c|c|c|}
\hline \multirow[b]{2}{*}{ Adubo } & \multirow[b]{2}{*}{ Nível } & \multirow[b]{2}{*}{$\begin{array}{c}\text { Ele- } \\
\text { mento } \\
\mathrm{kg} / \mathrm{Ha}\end{array}$} & \multicolumn{4}{|c|}{ Aplicações dos Adubos } \\
\hline & & & $\begin{array}{l}1 .^{\mathrm{a}} \text { aplic. } \\
\mathrm{g} / \text { parc. } \\
1400 \mathrm{ml} \\
\text { de água }\end{array}$ & $\begin{array}{l}2 .^{a} \text { aplic. } \\
\mathrm{g} / \text { parc./ } \\
1600 \mathrm{ml} \\
\text { de água }\end{array}$ & $\begin{array}{l}3 .^{a} \text { aplic. } \\
\mathrm{g} / \text { parc./ } \\
1600 \mathrm{ml} \\
\text { de água }\end{array}$ & $\begin{array}{l}\text { Total } \\
\mathrm{g} / \text { parc. }\end{array}$ \\
\hline \multirow{4}{*}{ Uréia } & 0 & 0,00 & 0,000 & 0,000 & 0,000 & 0,000 \\
\hline & 1 & 20,00 & 21,739 & 24,844 & 24,844 & 71,427 \\
\hline & 2 & 40,00 & 43,478 & 49,688 & 49,688 & 142,854 \\
\hline & 3 & 60,00 & 65,217 & 74,533 & 74,533 & 214,283 \\
\hline \multirow{4}{*}{$\begin{array}{l}\text { Super- } \\
\text { Fosfato } \\
\text { Concen- } \\
\text { trado }\end{array}$} & 0 & 0,00 & 0,000 & 0,000 & 0,000 & 0,000 \\
\hline & 1 & 20,00 & 26,666 & 30,475 & 30,475 & 87,616 \\
\hline & 2 & 40,00 & 53,333 & 60,850 & 60,850 & 175,033 \\
\hline & 3 & 60,00 & 79,999 & 91,325 & 91,325 & 262,649 \\
\hline \multirow{3}{*}{$\begin{array}{l}\text { Cloreto } \\
\text { de }\end{array}$} & 0 & 0,00 & 0,000 & 0,000 & 0,000 & 0,000 \\
\hline & 1 & 20,00 & 16,666 & 19,047 & 19,047 & 55,760 \\
\hline & 2 & 40,00 & 33,333 & 38,094 & 38,094 & 109,521 \\
\hline Potássio & 3 & 60,00 & 49,999 & 57,141 & 57,141 & 164,281 \\
\hline
\end{tabular}

No caso do superfosfato, êste adubo foi triturado em morteiro de porcelana e colocado em água destilada, submetido à agitação durante 15 min., com agitador magnético; a seguir foi filtrado e no filtrado, foi determinado o teor de $\mathrm{P}_{2} 0_{5}$, encontrando-se 37,5\%. $\mathrm{O}$ cálculo para as doses de fósforo a ser aplicado foram feitas em base a essa percentagem (veja a tabela III). 
$\mathrm{O}$ valor $\mathrm{pH}$ das soluções foi de 6,9, 3,4 e 6,3 para uréia, o superfosfato concentrado e o cloreto de potássio, respectivamente.

Em cada aplicação das diversas doses de adubos, utilizou-se uma solução do espalhante adesivo "Novapal" a $0,2 \%$.

As soluções eram preparadas um dia antes de cada pulverização e guardadas em frascos de vidro; no momento de cada pulverização eram colocadas no depósito de pulverizador e a pressão de saida para pulverizar eram mantida constante pelo contrôle da válvula do compressor do ar e da válvula do manômetro adatado ao depósito do pulverizador.

Cada bloco foi pulverizado em separado, começando-se sempre com a solução do nutriente menos concentrado. Após cada pulverização todo o sistema de pulverização era lavado com água destilada.

\section{Tratos culturais}

Aplicou-se o herbicida Treflan (a,a,a-trifluoro-2,6-dinitro-N-N-dipropil-p-toluidina), em pré-plantio, em 11 e 12 de novembro de 1968, na dose de 2 1/Ha em 6001 de água.

Êste herbicida não se revelou muito eficiente em nossas condições de trabalho, sendo necessário 3 capinas manuais aos 4, 30 de dezembro de 1968 e 28 de janeiro de 1969.

O desbaste foi feito em 19 de dezembro de 1968, deixando-se na fileira 25 plantas, o que corresponde a 100 plantas por parcela e a 5 plantas por metro.

\section{Tratamento contra pragas}

Quarenta e cinco dias após a germinação, notou-se um ataque de vírus (Mosaico), em 0,65\%, o que determinou o arranque de algumas plantas em algumas das parcelas. Nesta mesma época, surgiu o "pulgão" (Aphis gossypii, GLOVER, 1876), que foi combatido com uma pulverização de Metasystox a 0,05\% em 7 de janeiro de 1969.

Setenta e cinco dias após a germinação, constatou-se uma leve infestação de curuquerê (Alabama argillacea, Hubn, 1823) e Manchadores (Dysdercus spp), sendo necessário um primeiro polvilhamento com DDT a $10 \%$ mais Parathion a 1,5\%, e um segundo aos 113 dias para contrôle de pragas tardias com a mesma mistura anterior, não sendo necessário fazer-se mais aplicações, conforme foi planejada inicialmente. 


\section{Diagnose foliar}

\section{Amostragem de pecíolos}

Fizeram-se duas amostragens de pecíolos de ramos produtivos a primeira aos 86 dias após a germinação, portanto 10 dias após a segunda aplicação da pulverização foliar; a segunda aos 116 dias após a germinação, portanto 10 dias após a terceira aplicação da pulverização foliar.

Foram colhidos ao acaso, 20 pecíolos das duas fileiras centrais de cada parcela.

Considerou-se como fôlha de ramo produtivo a fôlha madura localizada sôbre ramos produtivos situados no terço médio do algodoeiro, apanhando-se a fôlha debaixo de uma flor aberta ou de uma maçã em formação e fôlha de ramo não produtiva, à fôlha nascida diretamente do caule situada no terço médio do algodoeiro (PREVOT e OLLAGNIER, 1956, MELLO, 1958). A hora para as amostragens foi sempre a mesma. Bloco A, de 7:30 a 9:00 horas, Bloco B, de 12:00 a 13:00 horas e Bloco C, de 9:00 a 10:30 horas.

\section{Análises químicas dos pecíolos}

Os peciólos foram lavados com água destilada, enxugados com papel de filtro; a seguir colocados em saquinhos de papel e postos a secar em estufa a $65-70^{\circ} \mathrm{C}$. Após 4 dias, os pecíolos foram moidos no micromoinho "Wiley".

Sôbre o material moido e pesado, procedeu-se às análises químicas. A determinação do nitrogênio foi feita pelo método do micro Kjeldahl, descrito em MALAVOLTA, 1967. Para a determinação do fósforo e do potássio foi feita inicialmente a digestão nitro-perclórica do material vegetal. No extrato nitro-perclórico, determinou-se o fósforo pelo método fotocolorimétrico descrito por LOTT et al., 1956; e o potássio pelo método espectrofotométrico de absorção atômica, na diluição de 1:5000, escala 1, de acôrdo com as instruções do manual da Perkin-Elmer, Modêlo 303.

\section{Colheita}

Foi necessário fazer-se duas colheitas, a primeira aos 150-153 dias após germinação e a segunda aos 179-182 dias após a germinação.

Foram escolhidas as duas linhas centrais de cada parcela, deixando de colher três plantas das pontas dessas linhas.

Para cada colheita, o algodão em caroço foi apanhado dos capulhos maduros e completamente abertos, os quais foram colocados em sacos plásticos, a seguir levados ao terreiro para secagem e posteriormente pesados e ensacados. Finalmente, foi reunido o produto das duas colheitas. 
Durante as colheitas foi contado o número de plantas e de capulhos da área útil de cada parcela.

\section{Análise Estatística}

A análise estatística dos dados foi feita segundo SNEDECOR, 1948, PIMENTEL GOMES, 1966 e GRANER, 1966.

\section{Resultados e discussão}

Análise do solo - Os valores obtidos da análise do solo encontram-se na Tabela III. Como se pode verificar, trata-se de um solo argiloso, de valor $\mathrm{pH}$ 6,0-6,3, ótimo para o desenvolvimento do algodoeiro. $O$ teor de matéria orgânica (M.O.) e o de nitrogênio total é alto. $O$ teor de fósforo solúvel é de baixo para médio. $O$ teor de potássio é de médio para alto. Os teores trocáveis de cálcio são médios e os de magnésio altos.

\section{Produção de algodão em carôço}

Os dados da produção de algodão em carôço podem ser vistos na Tabela IV.

TABELA IV - Produção de algodão em caroço em $\mathrm{kg} /$ parcela.

\begin{tabular}{|c|c|c|c|c|}
\hline \multirow{2}{*}{ Tratamentos } & \multicolumn{3}{|c|}{ Blocos } & \multirow{2}{*}{ Média } \\
\hline & A & B & C & \\
\hline $\mathrm{N}_{0} \mathrm{P}_{0} \mathrm{~K}_{0}$ & 2,32 & 2,24 & 2,92 & 2,49 \\
\hline $\mathrm{N}_{1} \mathrm{P}_{3} \mathrm{~K}_{3}$ & 1,98 & 1,23 & 3,07 & 2,09 \\
\hline $\mathrm{N}_{3} \mathrm{P}_{1} \mathrm{~K}_{3}$ & 2,62 & 1,31 & 2,76 & 2,23 \\
\hline $\mathrm{N}_{3} \mathrm{P}_{3} \mathrm{~K}_{1}$ & 2,67 & 2,42 & 2,73 & 2,61 \\
\hline $\mathrm{N}_{3} \mathrm{P}_{3} \mathrm{~K}_{3}$ & 2,41 & 2,34 & 2,94 & 2,56 \\
\hline $\mathrm{P}_{3} \mathrm{~K}_{3}+\mathrm{N}_{0} *$ & 2,36 & 2,44 & 3,13 & 2,64 \\
\hline $\mathrm{P}_{3} \mathrm{~K}_{3}+\mathrm{N}_{1}^{*}$ & 2,18 & 2,79 & 2,91 & 2,63 \\
\hline $\mathrm{P}_{3} \mathrm{~K}_{3}+\mathrm{N}_{2} *$ & 2,35 & 2,87 & 2,92 & 2,71 \\
\hline $\mathrm{P}_{3} \mathrm{~K}_{3}+\mathrm{N}_{3} *$ & 2,35 & 2,00 & 2,63 & 2,33 \\
\hline $\mathrm{N}_{3} \mathrm{~K}_{3}+\mathrm{P}_{0}^{\prime \prime} *$ & 2,44 & 2,56 & 2,71 & 2,57 \\
\hline $\mathrm{N}_{3} \mathrm{~K}_{3}+\mathrm{P}_{1} *$ & 2,20 & 2,89 & 2,96 & 2,68 \\
\hline $\mathrm{N}_{3} \mathbf{K}_{3}+\mathrm{P}_{2} *$ & 1,88 & 2,53 & 3,30 & 2,57 \\
\hline $\mathrm{N}_{3} \mathrm{~K}_{3}+\mathrm{P}_{3} *$ & 1,88 & 3,38 & 2,97 & 2,74 \\
\hline $\mathrm{N}_{3} \mathrm{P}_{3}+\mathrm{K}_{0}^{3} *$ & 2,30 & 2,92 & 2,54 & 2,59 \\
\hline $\mathrm{N}_{3} \mathrm{P}_{3}+\mathrm{K}_{1} *$ & 2,48 & 2,29 & 3,39 & 2,72 \\
\hline $\mathrm{N}_{3} \mathrm{P}_{3}+\mathrm{K}_{2} *$ & 2,59 & 2,49 & 2,82 & 2,63 \\
\hline $\mathrm{N}_{3} \mathrm{P}_{3}+\mathrm{K}_{3} *$ & 2,39 & 2,52 & 3,22 & 2,71 \\
\hline
\end{tabular}

* Os adubos foram aplicados nas folhas. 
Para o cálculo do ajuste das médias de produção por tratamento, fixou-se em 38 o número de plantas por área útil da parcela; para isso utilizou-se a seguinte fórmula: $\stackrel{\Lambda}{Y}=\bar{y} i-{ }_{b}\left(\bar{X}_{i} \bar{X}\right)$; onde $\bar{X}_{i}$ e $\overline{\mathrm{Y}}_{\mathrm{i}}$ são médias de número total de plantas colhidas e produção respectivamente do tratamento em questão, $\overline{\mathrm{X}}$ é a média geral do número total de plantas colhidas $(\overline{\mathrm{X}}=37,1112)$ e b é a regressão dos desvios.

A análise da variância dos dados de produção (Tabela V) mostra que não há diferença estatística entre nenhum desdobramento para tratamentos.

TABELA V - Análise da variancia da prođução

\begin{tabular}{|c|c|c|c|}
\hline Causa de variação & G. L. & F. & \\
\hline Tratamentos & 16 & 0,655 & \\
\hline Nas folhas & 11 & 0,245 & \\
\hline Doses（D) & 3 & & 0,086 \\
\hline Adubos (A) & 2 & & 0,152 \\
\hline $\mathrm{D} \times \mathrm{A}$ & 6 & & 0,357 \\
\hline No solo & 4 & 1,000 & \\
\hline Máxima Vs Testemunha & 1 & & 0,046 \\
\hline Entre doses intermediárias & 2 & & 1,404 \\
\hline (Máxima e testemunha) Vs & & & \\
\hline Doses intermediárias & 1 & & 1,139 \\
\hline Nas folhas Vs no solo & 1 & 3,709 & \\
\hline Blocos & 2 & & \\
\hline Resíduo & 32 & & \\
\hline Total & 50 & & \\
\hline
\end{tabular}

C. $\mathrm{V} .=15,17 \%$

Na Tabela VII, na segunda coluna, estão as médias ajustadas aos tratamentos em $\mathrm{kg} /$ parcela, na terceira coluna, a produção em $\mathrm{kg} / \mathrm{Ha}$ considerando-se uma população de 50000 plantas/Ha, e na quarta coluna a percentagem relativa em relação ao tratamento testemunha. Convém destacar o aumento relativo de 17,15\%,20,50\% e $23,01 \%$, obtidos com os tratamentos $\mathrm{N}_{3} \mathrm{P}_{3}+\mathrm{K}_{2}{ }^{*} \mathrm{~N}_{3} \mathrm{~K}_{3}+\mathrm{P}_{3} * \mathrm{e}$ $\mathrm{P}_{3} \mathrm{~K}_{3}+\mathrm{N}_{2}^{*}$, respectivamente. 
No presente experimento, a média da produção alcançada foi de $3366,09 \mathrm{~kg} / \mathrm{Ha}$, bem superior à média do Estado de São Paulo, que foi para os anos 1965, 1966 e $1967 \mathrm{de} \mathrm{993,28} \mathrm{kg/Ha,} \mathrm{1039,30} \mathrm{kg/Ha}$ e $851,73 \mathrm{~kg} / \mathrm{Ha}$, respectivamente, em acôrdo com os dados do Anuário Estatístico do Brasil, 1968, publicado pela Fundação I.B.G.E., Instituto Brasileiro de Estatística.

Podia-se admitir que as condições climáticas teriam influência sôbre a produção, porém os dados da Tabela VI, mostram claramente que tanto a precipitação pluviométrica, como a temperatura e a insolação foram propícias para o bom desenvolvimento da cultura (CORDOZIER, 1962 e ORTOLANI et al., 1965).

TABELA VI - Dados metereológicos observados durante o experimento.

\begin{tabular}{|c|c|c|c|c|c|c|}
\hline \multirow{2}{*}{ Anos } & \multirow{2}{*}{ Meses } & \multicolumn{2}{|c|}{ Temperatura ${ }^{\circ} \mathrm{C}$} & \multirow{2}{*}{$\begin{array}{c}\text { Umidade } \\
\text { Relativa } \\
\% \%\end{array}$} & \multirow{2}{*}{$\begin{array}{l}\text { Precipi- } \\
\text { tação } \\
\mathrm{mm}\end{array}$} & \multirow{2}{*}{$\begin{array}{c}\text { Insolação } \\
(\mathrm{h})\end{array}$} \\
\hline & & Máxima & Mínima & & & \\
\hline \multirow[t]{2}{*}{1968} & Nov. & 31,7 & 17,4 & 62 & 62,8 & 214,1 \\
\hline & Dez. & 30,2 & 18,6 & 73 & 235,5 & 242,7 \\
\hline \multirow[t]{5}{*}{1969} & Jan. & 32,1 & 18,8 & 73 & 126,1 & 245,1 \\
\hline & Fev. & 32,1 & 19,8 & 75 & 40,9 & 156,8 \\
\hline & Mar. & 31,9 & 17,8 & 72 & 173,8 & 237,3 \\
\hline & Abr. & 28,5 & 14,1 & 73 & 53,1 & 230,5 \\
\hline & Mai. & 27,3 & 11,3 & 70 & 36,6 & 204,1 \\
\hline
\end{tabular}

Procurando explicar a falta de reação do algodoeiro às adubações feitas, verifica-se que o teor de nitrogênio do solo onde foi feito o presente experimento, foi alto $(0,18 \% \mathrm{~N})$, como se pode observar na Tabela III, VERDADE et al., 1965, propuseram que se podia aceitar que acima de um teor de nitrogênio de $0,16 \%$, pode-se esperar baixa probabilidade de reacão do algodoeiro na terra roxa. Embora que no caso da análise do nitrogênio total do solo, impõe-se certa reserva no sentido de que, mesmo com teores superiores aos já mencionados, possa haver uma reação à adubação nitrogenada, no nosso caso, porém, devemos atribuir a falta de reação à adubação nitrogenada tanto no solo como na fôlha a êste alto teor encontrado.

Em relação ao fósforo os teores encontrados no solo utilizado no presente experimento foi de médio para baixo $(0,08-0,12 \mathrm{e} \mathrm{mg} /$ $100 \mathrm{~g}$ de solo de $\mathrm{PO}_{4}^{-3}$ ). VERDADE et al., 1965, indicaram que para os solos argilosos especialmente terra roxa, com nível igual ou superior a $0,17 \mathrm{e} \mathrm{mg} / 100 \mathrm{~g}$ de solo, encontra-se baixa probabilidade de 
TABELA VII - Médias de produção ajustada por tratamento.

\begin{tabular}{lccc}
\hline Tratamentos & $\begin{array}{c}\text { Média Ajustada } \\
\mathrm{kg} / \text { parcela }\end{array}$ & $\begin{array}{c}\text { Produção } \\
\text { kg/Ha }\end{array}$ & $\begin{array}{c}\text { Percentagem } \\
\text { Relativa }\end{array}$ \\
\hline \hline $\mathrm{N}_{0} \mathrm{P}_{0} \mathrm{~K}_{0}$ & 2,39 & 3144,73 & 100,00 \\
$\mathrm{~N}_{1} \mathrm{P}_{3} \mathrm{~K}_{3}$ & 2,08 & 2736,84 & 87,03 \\
$\mathrm{~N}_{3} \mathrm{P}_{1} \mathrm{~K}_{3}$ & 2,07 & 2723,68 & 86,61 \\
$\mathrm{~N}_{3} \mathrm{P}_{3} \mathrm{~K}_{1}$ & 2,66 & 3499,99 & 111,30 \\
$\mathrm{~N}_{3} \mathrm{P}_{3} \mathrm{~K}_{3}$ & 2,63 & 3460,52 & 110,04 \\
$\mathrm{P}_{3} \mathrm{~K}_{3}+\mathrm{N}_{0}$ & 2,42 & 3184,21 & 101,25 \\
$\mathrm{P}_{3} \mathrm{~K}_{3}+\mathrm{N}_{1}$ & 2,61 & 3434,21 & 109,25 \\
$\mathrm{P}_{3} \mathrm{~K}_{3}+\mathrm{N}_{2}$ & 2,88 & 3789,47 & 120,50 \\
$\mathrm{P}_{3} \mathrm{~K}_{3}+\mathrm{N}_{3}$ & 2,14 & 2815,79 & 89,54 \\
$\mathrm{~N}_{3} \mathrm{~K}_{3}+\mathrm{P}_{0}$ & 2,52 & 3315,79 & 105,44 \\
$\mathrm{~N}_{3} \mathrm{~K}_{3}+\mathrm{P}_{1}$ & 2,71 & 3565,79 & 113,39 \\
$\mathrm{~N}_{3} \mathrm{~K}_{3}+\mathrm{P}_{2}$ & 2,56 & 3368,42 & 107,11 \\
$\mathrm{~N}_{3} \mathrm{~K}_{3}+\mathrm{P}_{3}$ & 2,94 & 3868,42 & 123,01 \\
$\mathrm{~N}_{3} \mathrm{P}_{3}+\mathrm{K}_{0}$ & 2,68 & 3526,31 & 112,13 \\
$\mathrm{~N}_{3} \mathrm{P}_{3}+\mathrm{K}_{1}$ & 2,67 & 3513,16 & 111,71 \\
$\mathrm{~N}_{3} \mathrm{P}_{3}+\mathrm{K}_{2,}$ & 2,80 & 3684,21 & 117,15 \\
$\mathrm{~N}_{3} \mathrm{P}_{3}+\mathrm{K}_{3}$ & 2,73 & 3592,10 & 114,24 \\
\hline
\end{tabular}

* Os adubos foram aplicados nas folhas

reação do algodoeiro à adubação fosfatada. De acordo com os mesmos pesquisadores, quando os teores de fósforo solúvel no solo estiverem entre 0,07 e $0,14 \mathrm{e} \mathrm{mg} / 10 \mathrm{C} \mathrm{g}$ de solo, o que é nosso caso, a possibilidade de haver resposta à adubação fosfatada estará ao redor de $50 \%$; como já foi mencionado não houve resposta à adubação fosfatada.

Em relação ao potássio, o teor de $\mathrm{K}^{+}$foi de médio para alto (0,28-0,47 e mg/100g de solo). VERDADE et al., 1965, encontraram pequena reação ao potássio; das 209 experiencias conduzidas, somente 10 deram resultados positivos. Por outro lado, tentamos estabelecer a reação entre os teores trocáveis de cálcio e potássio no solo, $\mathrm{Ca}^{2+} / \mathrm{K}^{+}$, porque FUZATTO e FERRAZ, 1967, encontraram que esta relação mostrou-se como principal fator para explicar os efeitos provocados pela adubação potássica. Para valores acima de 20 desta relação, estes pesquisaḍores encontraram aumentos consideráveis na produção e estes foram tanto maiores quanto mais ampla for aquela relação. Ao contrário, valores daqueles quociente abaixo de 10 estiveram associados a respostas insignificantes ou frequentemente negativas. Estes mesmos pesquisadores consideram que o teor de po- 
tássio trocável, tomado isoladamente, pouco contribuiu para esclarecer o comportamento da adubação com este elemento.

No nosso caso, os valores da relação $\mathrm{Ca}^{+2} / \mathrm{K}^{+}$encontram-se entre 10,3 - 15,0, muito mais próximos do valor da relação 10 , onde não se encontram respostas significativas à adubação potássica.

\section{Diagnose Foliar}

Nas Tabelas VIII e IX, encontram-se os teores de nitrogenio, fósforo e potássio dos pecíolos das folhas de ramos produtivos e não produtivos, da primeira e segunda amostragem respectivamente.

Como não foi encontrada diferença na produção, era de se esperar que tampouco houvesse diferença entre os teores dos elementos, de cada amostragem, nos pecíolos de folhas do ramo correspondente.

TABELA VIII - Primeira amostragem dos teores médios de N, P e K por tratamento nos pecíolos das folhas.

\begin{tabular}{|c|c|c|c|c|c|c|}
\hline \multirow{2}{*}{ Tratamento } & \multicolumn{2}{|c|}{$\mathbf{N} \%$} & \multicolumn{2}{|c|}{ P \% } & \multicolumn{2}{|c|}{ K \% } \\
\hline & $\begin{array}{l}\text { ramo } \\
\text { produtivo }\end{array}$ & $\begin{array}{l}\text { ramo não } \\
\text { produtivo }\end{array}$ & $\begin{array}{l}\text { ramc, } \\
\text { produtivo }\end{array}$ & $\begin{array}{l}\text { ramo não } \\
\text { produtivo }\end{array}$ & $\begin{array}{c}\text { ramo } \\
\text { produ- } \\
\text { tivo }\end{array}$ & $\begin{array}{c}\text { ramo não } \\
\text { produ- } \\
\text { tivo }\end{array}$ \\
\hline $\mathrm{N}_{0} \mathrm{P}_{0} \mathrm{~K}_{0}$ & 1,357 & 1,125 & 0,150 & 0,098 & 3,256 & 2,495 \\
\hline $\mathrm{N}_{1} \mathrm{P}_{3} \mathrm{~K}_{3}$ & 1,335 & 1,111 & 0,139 & 0,096 & 3,706 & 2,615 \\
\hline $\mathrm{N}_{3} \mathrm{P}_{1} \mathrm{~K}_{3}$ & 1,353 & 1,195 & 0,125 & 0,089 & 3,930 & 2,118 \\
\hline $\mathrm{N}_{3} \mathrm{P}_{3} \mathrm{~K}_{1}$ & 1,279 & 1,181 & 0,151 & 0,100 & 3,365 & 2,654 \\
\hline $\mathrm{N}_{3} \mathrm{P}_{3} \mathrm{~K}_{3}$ & 1,368 & 1,200 & 0,150 & 0,099 & 3,562 & 2,780 \\
\hline $\mathrm{P}_{3} \mathrm{~K}_{3}+\mathrm{N}_{0} *$ & 1,419 & 1,101 & 0,154 & 0,105 & 3,250 & 2,369 \\
\hline $\mathrm{P}_{3} \mathrm{~K}_{3}+\mathrm{N}_{1} *$ & 1,372 & 1,185 & 0,149 & 0,102 & 3,157 & 2,488 \\
\hline $\mathrm{P}_{3} \mathrm{~K}_{3}+\mathrm{N}_{2} *$ & 1,223 & 1,083 & 0,154 & 0,103 & 3,436 & 2,701 \\
\hline $\mathrm{P}_{3} \mathrm{~K}_{3}+\mathrm{N}_{3} *$ & 1,419 & 1,218 & 0,155 & 0,105 & 3,234 & 2,391 \\
\hline $\mathrm{N}_{3} \mathrm{~K}_{3}+\mathrm{P}_{0} *$ & 1,428 & 1,162 & 0,155 & 0,106 & 3,357 & 2,517 \\
\hline $\mathrm{N}_{3} \mathrm{~K}_{3}+\mathrm{P}_{1} *$ & 1,372 & 1,157 & 0,155 & 0,109 & 3,503 & 2,712 \\
\hline $\mathrm{N}_{3} \mathrm{~K}_{3}+\mathrm{P}_{2} *$ & 1,447 & 1,129 & 0,151 & 0,103 & 3,213 & 2,259 \\
\hline $\mathbf{N}_{3} \mathrm{~K}_{3}+\mathrm{P}_{3} *$ & 1,377 & 1,139 & 0,160 & 0,112 & 3,475 & 2,490 \\
\hline $\mathrm{N}_{3} \mathrm{P}_{3}+\mathrm{K}_{0} *$ & 1,358 & 1,139 & 0,175 & 0,116 & 4,081 & 3,458 \\
\hline $\mathrm{N}_{3} \mathrm{P}_{3}+\mathrm{K}_{1} *$ & 1,391 & 1,129 & 0,163 & 0,115 & 3,507 & 3,057 \\
\hline $\mathrm{N}_{3} \mathrm{P}_{3}+\mathrm{K}_{2} *$ & 1,395 & 1,087 & 0,154 & 0,105 & 3,638 & 2,826 \\
\hline $\mathrm{N}_{3} \mathrm{P}_{3}+\mathrm{K}_{3} *$ & 1,414 & 1,157 & 0,162 & 0,106 & 3,981 & 3,489 \\
\hline
\end{tabular}

C.V. $=8,21 \%$ C.V. $=7,24 \%$ C.V. $=14,57 \%$ C.V. $=13,27 \%$ C.V. $17,92 \%$ C.V. $=24,14 \%$ $F=0,724$ n.s. $F=0,696$ n.s. $F=0,600$ n.s. $F=0,717$ n.s. $F=0,595$ n.s. $F=0,867$ n.s.

* Adubo aplicado nas folhas. 
TABELA IX - Segunda amostragem dos teores médios de N, P e K por tratamento nos pecíolos das folhas.

\begin{tabular}{|c|c|c|c|c|c|c|}
\hline \multirow{2}{*}{ Tratamento } & \multicolumn{2}{|c|}{$\mathrm{N} \%$} & \multicolumn{2}{|c|}{$\mathrm{P} \%$} & \multicolumn{2}{|c|}{ K \% } \\
\hline & $\begin{array}{l}\text { ramo } \\
\text { produtivo }\end{array}$ & $\begin{array}{l}\text { ramo não } \\
\text { produtivo }\end{array}$ & $\begin{array}{l}\text { ramo } \\
\text { produtivo }\end{array}$ & $\begin{array}{l}\text { ramo não } \\
\text { produtivo }\end{array}$ & $\begin{array}{c}\text { ramo } \\
\text { produ- } \\
\text { tivo }\end{array}$ & $\begin{array}{c}\text { ramo não } \\
\text { produ- } \\
\text { tivo }\end{array}$ \\
\hline $\mathrm{N}_{0} \mathrm{P}_{0} \mathrm{~K}_{0}$ & 1,136 & 0,937 & 0,122 & 0,099 & 2,846 & 2,282 \\
\hline $\mathrm{N}_{1} \mathrm{P}_{3} \mathrm{~K}_{3}$ & 1,195 & 0,994 & 0,131 & 0,101 & 3,235 & 2,570 \\
\hline $\mathrm{N}_{3} \mathrm{P}_{1} \mathrm{~K}_{3}$ & 1,115 & 0,993 & 0,111 & 0,091 & 3,355 & 2,637 \\
\hline $\mathrm{N}_{3} \mathrm{P}_{3} \mathrm{~K}_{1}$ & 1,097 & 0,896 & 0,121 & 0,100 & 2,816 & 2,295 \\
\hline $\mathrm{N}_{3} \mathrm{P}_{3} \mathrm{~K}_{3}$ & 1,198 & 1,014 & 0,126 & 0,102 & 3,214 & 2,480 \\
\hline $\mathrm{P}_{3} \mathrm{~K}_{3}+\mathrm{N}_{0} *$ & 1,073 & 0,989 & 0,126 & 0,103 & 3,306 & 2,069 \\
\hline $\mathrm{P}_{3} \mathrm{~K}_{3}+\mathrm{N}_{1} *$ & 1,139 & 1,055 & 0,124 & 0,103 & 2,564 & 1,893 \\
\hline $\mathrm{P}_{3} \mathrm{~K}_{3}+\mathrm{N}_{2} *$ & 1,195 & 0,961 & 0,134 & 0,104 & 3,044 & 2,300 \\
\hline $\mathrm{P}_{3} \mathrm{~K}_{3}+\mathrm{N}_{3}{ }^{*}$ & 1,269 & 1,017 & 0,127 & 0,106 & 2,882 & 2,157 \\
\hline $\mathrm{N}_{3} \mathrm{~K}_{3}+\mathrm{P}_{0} *$ & 1,115 & 0,999 & 0,126 & 0,097 & 2,577 & 1,910 \\
\hline $\mathrm{N}_{3} \mathrm{~K}_{3}+\mathrm{P}_{1} *$ & 1,083 & 0,999 & 0,129 & 0,107 & 3,045 & 2,315 \\
\hline $\mathrm{N}_{3} \mathrm{~K}_{3}+\mathrm{P}_{2}^{*}$ & 1,195 & 0,971 & 0,140 & 0,115 & 2,726 & 2,087 \\
\hline $\mathrm{N}_{3} \mathrm{~K}_{3}+\mathrm{P}_{3} *$ & 1,148 & 1,027 & 0,148 & 0,119 & 2,744 & 2,173 \\
\hline $\mathrm{N}_{3} \mathrm{P}_{3}+\mathrm{K}_{0}{ }^{*}$ & 1,251 & 1,047 & 0,149 & 0,118 & 3,988 & 3,348 \\
\hline $\mathrm{N}_{3} \mathrm{P}_{3}+\mathrm{K}_{1} *$ & 1,232 & 0,989 & 0,149 & 0,122 & 3,724 & 2,890 \\
\hline $\mathrm{N}_{3} \mathrm{P}_{3}+\mathrm{K}_{2} *$ & 1,129 & 1,027 & 0,125 & 0,098 & 3,277 & 2,889 \\
\hline $\mathbf{N}_{3} P_{3}+K_{3}^{*}$ & 1,185 & 0,999 & 0,144 & 0,110 & 3,958 & 3,489 \\
\hline
\end{tabular}

C.V. $=8,09 \%$ C.V. $=14,70$ C.V. $=16,79 \%$ C.V. $=16,28 \%$ C.V. $=22,98 \%$ C.V. $=32,02 \%$ $F=1,146$ n.s. $F=0,374$ n.s. $F=0,762$ n.s. $F=0,728$ n.s. $F=1,116$ n.s. $F=1,048$ n.s.

* Adubo aplicado nas folhas.

Os teores médios de nitrogenio, fósforo e potássio encontram-se na Tabela X.

Observa-se que os teores dos elementos diminuem da primeira para a segunda amostragem, exceto o fósforo nos pecíolos de folhas nos ramos não produtivos. As médias dos teores obtidos para o potássio, foram mais elevados do que aquêles obtidos por MELLO et al., 1960 e se aproximam muito mais daqueles obtidos por PAGE et al., $1963 \mathrm{~b}$, devendo assinalar contudo, que os teores do potássio trocável encontrados nos solos utilizados por êstes pesquisadores, eram baixos da ordem de 0,07-0,09 e mg/g de solo, porém os teores encontrados por MELLO et al., 1960 eram de 1,93 no pecíolo de folhas de ramos produtivos e 1,85 nos pecíolos de folhas de ramos não

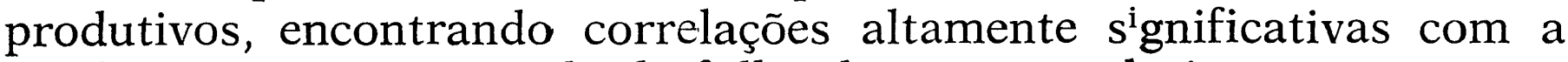
produção, tanto no pecíolo da folha do ramo produtivo como no não 


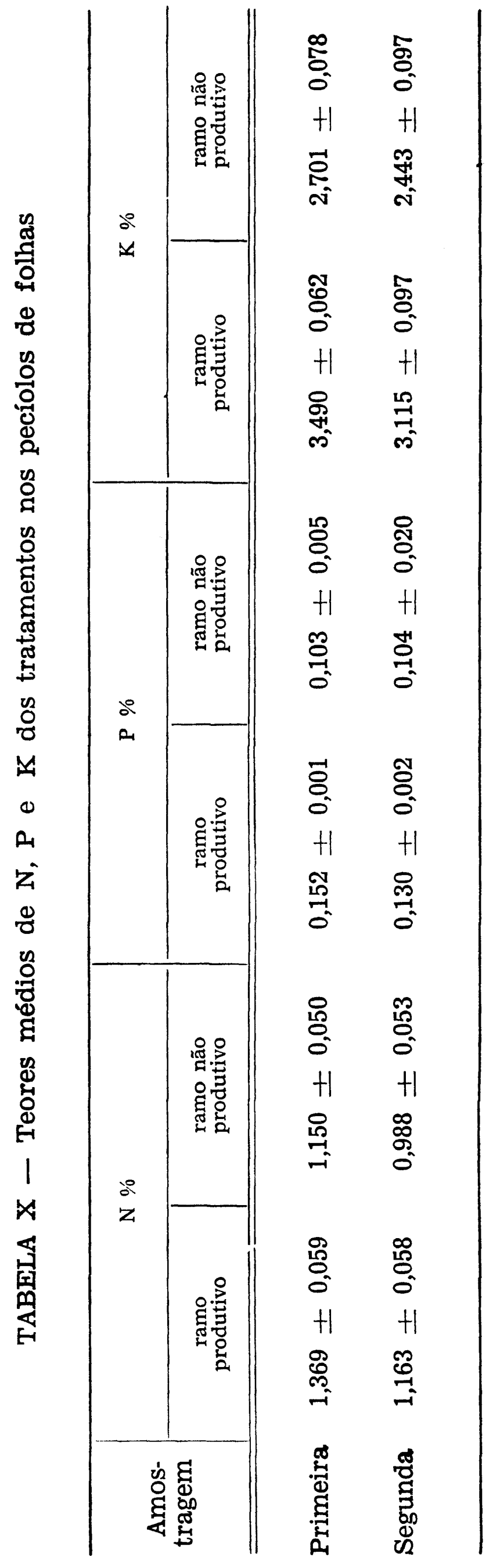


produtivo, porém as correlações entre os pecíolos das folhas de ambos ramos foram significativos na primeira amostragem (90 dias após germinação).

No caso, encontramos correlações totais significativas dos teores de potássio com produção na primeira amostragem para pecíolos de folhas de ramos não produtivos e na segunda amostragem para pecíolos de folhas de ambos ramos. Não foi encontrada correlação significativa entre os pecíolos de folhas de ambos os ramos nas duas amostragens.

Foram encontradas também correlações totais entre os teores de fósforo e produção: na primeira amostragem, para pecíolos de ambos ramos e na segunda amostragem, somente para pecíolos de folhas de ramos não produtivos.

Quanto ao nitrogenio, não foi encontrada nenhuma correlação.

Nas comparações entre os coeficientes das correlações totais de fósforo e potássio, não foi encontrada significancia estatística alguma.

TABELA XI - Coeficientes de correlações totais entre a produção e os teores de $\mathrm{N}, \mathrm{P}$ e $\mathrm{K}$ nos pecíolos de folhas de ramos produtivos e não produtivos.

\begin{tabular}{|c|c|c|c|c|}
\hline \multirow[b]{2}{*}{ Parte da folha } & \multicolumn{2}{|c|}{ P\% x Produção } & \multicolumn{2}{|c|}{ K\% x Produção } \\
\hline & $\begin{array}{c}1 .^{\mathrm{a}} \\
\text { amostragem }\end{array}$ & $\begin{array}{c}2 .^{\mathrm{a}} \\
\text { amostragem }\end{array}$ & $\begin{array}{c}1 .^{\mathrm{a}} \\
\text { amostragem }\end{array}$ & $\begin{array}{c}2 \mathrm{a}^{\mathrm{a}} \\
\text { amostragem }\end{array}$ \\
\hline $\begin{array}{l}\text { Pecíolo de ramo } \\
\text { produtivo }\end{array}$ & $\mathrm{r}=0,542$ & $r=0,354$ & $r=0,295$ & $r=0,430$ \\
\hline $\begin{array}{l}\text { Pecíolo de ramo } \\
\text { não produtivo }\end{array}$ & $r=0,436$ & $r=0,319$ & $r=0,460$ & $r=0,388$ \\
\hline
\end{tabular}

\section{CONCLUSÕES}

Os resultados obtidos mostraram que:

1 - Em relação ao número de plantas e ao número total de capulhos colhidos, não foi encontrada diferença estatística em nenhum dos desdobramentos feitos para tratamentos.

2 - Quanto à produção do algodão em caroço, não foi encontrada diferença estatística. A média alcançada foi de 3.366,09 $\mathrm{kg} / \mathrm{Ha}$. Porém, convém destacar que na porcentagem relativa em relação ao tratamento testemunha, houve um aumento de $17,15 \%, 20,50 \%$ e $23,01 \%$, obtidos com tratamentos $\mathrm{N}_{3} \mathrm{P}_{3}+\mathrm{K}_{2}^{*}, \mathrm{~N}_{3} \mathrm{~K}_{3}+\mathrm{P}_{3}$ e $\mathrm{P}_{3} \mathrm{~K}_{3}+\mathrm{N}_{2} *$ respectivamente. 
3 - As análises da covariância, confirmam os resultados encontrados nos itens 1 e 2 , sendo as correlações, entre o desvio do número de plantas colhidas e o desvio da produção, $\mathrm{r}=0,549 * *$ e entre o desvio do número de capulhos colhidos e o desvio da produção, $r=0,887^{* *}$ e entre o desvio do número de plantas e o número de capulhos $r=0,569^{* *}$.

4 - Os teores médios percentuais de nitrogênio, fósforo e potássio, encontrados nos pecíolos são os seguintes:

\begin{tabular}{|c|c|c|c|}
\hline \multirow{3}{*}{$\begin{array}{l}\text { AMOS- } \\
\text { TRAGENS }\end{array}$} & \multicolumn{3}{|c|}{ PECIOLOS DE FOLHAS } \\
\hline & \multicolumn{3}{|c|}{ Ramos produtivos } \\
\hline & $N(\%)$ & $\mathrm{P}(\%)$ & $\mathrm{K}(\%)$ \\
\hline $1 .^{a}$ & $1,369 \pm 0,059$ & $0,152 \pm 0,001$ & $3,490 \pm 0,062$ \\
\hline $2 .^{a}$ & $1,163 \pm 0,058$ & $0,130 \pm 0,002$ & $3,115 \pm 0,097$ \\
\hline \multirow{2}{*}{$\begin{array}{l}\text { AMOS- } \\
\text { TRAGENS }\end{array}$} & \multicolumn{3}{|c|}{ Ramos não produtivos } \\
\hline & $\mathbf{N}(\%)$ & $\mathbf{P}(\%)$ & $\mathbf{K}(\%)$ \\
\hline $1 .^{a}$ & $1,150 \pm 0,050$ & $0,103 \pm 0,005$ & $2,701 \pm 0,078$ \\
\hline $2 .^{a}$ & $0,988 \pm 0,053$ & $1,104 \pm 0,020$ & $2,443 \pm 0,097$ \\
\hline
\end{tabular}

Não foram encontradas diferenças estatísticas nos teores deste tres nutrientes nos tratamentos, de cada amostragem, nos pecíolos de folhas de ramo correspondente. As amostragens foram feitas aos 86 e aos 116 dias após a germinação para a primeira e segunda amostragem respectivamente.

5 - Foram encontradas correlações totais significativas dos teores de potássio com produção na primeira amostragem para os pecíolos de folhas de ramo não produtivo e na segunda amostragem para pecíolos de folhas de ambos os ramos:

\begin{tabular}{lcc}
\hline PECIOLOS & $\begin{array}{c}\text { PRIMEIRA } \\
\text { AMOSTRAGEM }\end{array}$ & $\begin{array}{c}\text { SEGUNDA } \\
\text { AMOSTRAGEM }\end{array}$ \\
\hline $\begin{array}{l}\text { Folhas de ramo } \\
\text { produtivo }\end{array}$ & $\mathrm{r}=0,295$ & $\mathrm{r}=0,430$ \\
$\begin{array}{l}\text { Folhas de ramo } \\
\text { não produtivo }\end{array}$ & $\mathrm{r}=0,460$ & $\mathrm{r}=0,388$ \\
\hline
\end{tabular}


Também foram encontradas correlações totais entre os teores de fósforo e produção; na primeira amostragem, para pecíolos de ambos os ramos e na segunda amostragem, somente para pecíolos de ramos produtivos.

\begin{tabular}{lcc}
\hline PECIOLOS & $\begin{array}{c}\text { PRIMEIRA } \\
\text { AMOSTRAGEM }\end{array}$ & $\begin{array}{c}\text { SEGUNDA } \\
\text { AMOSTRAGEM }\end{array}$ \\
\hline \hline $\begin{array}{l}\text { Folhas de ramo } \\
\text { produtivo }\end{array}$ & $\mathrm{r}=0,542$ & $\mathrm{r}=0,354$ \\
$\begin{array}{l}\text { Folhas de ramo } \\
\text { não produtivo }\end{array}$ & $\mathrm{r}=0,436$ & $\mathrm{r}=0,319$ \\
\hline
\end{tabular}

Não foi encontrada diferença estatística nas duas amostragens, entre as correlações dos pecíolos de folhas de ambos os ramos.

\section{SUMMARY}

EFFECT OF FOLIAR APPLICATION OF NITROGEN, PHOSPHORUS AN'D POTASSIUM IN COTTON (Gossipium hirsutum, L. var. I.A.C. 12) AS EVALUATED BY YIELD AND FOLIAR ANALYSIS

This work was carried out on latosolic soil type, called "terra roxa estruturada", Luiz de Queiroz serie. It was installed in November 1968 and was finished in May 1969, using the I.C.A. 12 (G. hirsutum L.) variety.

The objectives of this work were:

1 - Evaluate the effect of foliar spraying in the yield increase.

2 - Evaluate the effect of foliar spraying by foliar diagnosis, and determine correlations between the yield and nitrogen, phosphorus and potassium concentrations in the petioles of leaves of productive and unproductive branches.

3 - The experimental design consisted of complete randomized blocks with 3 replications with part of the treatments in a $4 \times 3$ factorial arrangement; 4 representing the number of levels and 3 the number of fertilizers. Apart from these, 12 treatments were included: $\mathrm{N}_{0} \mathrm{P}_{0} \mathrm{~K}_{0}, \mathrm{~N}_{1} \mathrm{P}_{3} \mathrm{~K}_{3}, \mathrm{~N}_{3} \mathrm{P}_{1} \mathrm{~K}_{3}, \mathrm{~N}_{3} \mathrm{P}_{3} \mathrm{~K}_{1}$ and $\mathrm{N}_{3} \mathrm{P}_{3} \mathrm{~K}_{3}$. Each block consisted of 21 plots because the $\mathrm{N}_{0} \mathrm{P}_{0} \mathrm{~K}_{0}$ and $\mathrm{N}_{3} \mathrm{P}_{3} \mathrm{~K}_{3}$ treatments were replicates 3 times within each block, in order to increase the accuracy of the respective mean values. The levels of these elements were as follows. 
Level

0

1

2

3
$\mathrm{Kg}$ of the element/Ha

$$
\begin{array}{r}
0,00 \\
20,00 \\
40,00 \\
60,00
\end{array}
$$

In the soil and foliar fertilization the fertizer used as a source of nitrogen was urea $(46 \% \mathrm{~N})$, as a source of phosphorus concentred superphosphate $\left(45 \% \quad \mathrm{P}_{2} 0_{\overline{5}}\right)$ and as a source of potassium, potassium chloride $\left(60 \% \quad \mathrm{~K}_{2} 0\right)$.

The results obtained show that:

1 - No statistical differences were found in the production of branch cotton. Then mean value reached $3,366.09 \mathrm{~kg} / \mathrm{Ha}$. it should be pointed out, however, that in the relative percentage with respect to the check tratment there were increases of $17,15 \%, 20,50 \%$ and $23,01 \%$. These were obtained with the $\mathrm{N}_{3} \mathrm{P}_{3}+\mathrm{K}_{2}{ }^{*}, \mathrm{~N}_{3} \mathrm{~K}_{3}+\mathrm{P}_{3}^{*}$

\begin{tabular}{|c|c|c|c|}
\hline \multirow{3}{*}{ SAMPLING } & \multicolumn{3}{|c|}{ LEA F PE1TIOLES } \\
\hline & \multicolumn{3}{|c|}{ Productive branches } \\
\hline & $\mathbf{N}$ & $\mathrm{P}$ & $\mathrm{K}$ \\
\hline $1 .^{2}$ & $1,369 \pm 0,059$ & $0,152 \pm 0,001$ & $3,490 \pm 0,062$ \\
\hline $2 .^{\mathrm{a}}$ & $1,163 \pm 0,058$ & $0,130 \pm 0,002$ & $3,115 \pm 0,097$ \\
\hline \multirow{2}{*}{ SAMPLING } & \multicolumn{3}{|c|}{ Unproductive branches } \\
\hline & $\mathrm{N}$ & $\mathrm{P}$ & $\mathrm{K}$ \\
\hline $1 .^{a}$ & $1,150 \pm 0,050$ & $0,103 \pm 0,005$ & $2,701 \pm 0,078$ \\
\hline $2 .^{\mathrm{a}}$ & $0,988 \pm 0,053$ & $0,104 \pm 0,020$ & $2,443 \pm 0,097$ \\
\hline
\end{tabular}
and $\mathrm{P}_{3} \mathrm{~K}_{3}+\mathrm{N}_{2} *$ treatments respectively.

2 - The mean percentage concentrations of nitrogen, phosphorus and potassium which were found in the petioles were the following:

No statistical differences were found, for each sampling, in the concentrations of these three nutrients in the petiole of the respective branch. The first sampling was carried out 86 days after germination and the second 116 days after germination. 
3 - Total significant correlations were found in the percentages of potassium with yield in the first sampling for petioles of leaves of productive branches and in the second sampling for petioles of both productive and unproductive branches:

\begin{tabular}{lcc}
\hline PETIOLES & FIRST SAMPLING & SECOND SAMPLING \\
\hline Productive branch leaves & $r=0,295$ & $r=0,430^{*}$ \\
Unproductive branch leaves & $r=0,460^{*}$ & $r=0,388^{*}$ \\
\hline
\end{tabular}

Total correlations were also obtained between the phosphorus percentages and yield in the first sampling for petioles of both types of branches and in the second sampling just for petioles of productive branches:

PETIOLES

\begin{tabular}{lll}
\hline \hline Productive branch leaves & $\mathrm{r}=0,542^{* * *}$ & $\mathrm{r}=0,354^{*}$ \\
Unproductive branch leaves & $\mathrm{r}=0,436^{*}$ & $\mathrm{r}=0,319^{*}$ \\
\hline
\end{tabular}

No statistical difference was found, in relation to the type of sampling, between the correlations of the petioles of leaves of both types branches.

\section{LITERATURA CITADA}

ANONYME. 1962 Foliar application of nitrogen to cotton found impractical during fruting period. Agr. Chemicals, Avril p. 27-28 et 105 Coton et fibr. trop. 17 (3): 507-62.

BODADE, V. N. \& MADARIKAR, T. K. 1965 Relative effecacy of soil and spray application of $\mathrm{N}$ and $\mathrm{P}$ nutrients on cotton. Indian Cott. J., 19: 368-272.

BOYTON, D. 1954 Nutrition by foliar application. A. Rev. Pl. Physiol. 5: 31-54. BURKALOV, N. 1964 Traitement des feuilles de cotonnier par le phosphore. Rast. Nauk., Sofia, 1, p. $41-49$ (Emp. Cott. Grow. Rev., Oct. 1964, 41-4, p. 313).

BRAND, M. \& RICHEZ, F. 1963 Sur des pulvérisations foliares d'urés en culture cotonniére. Coton et fibr. trop., 18 (3): 281-3.

CATANI, R. A., GALLO, J. R. \& GARGANTINI, H. 1955 Amostragem do solo, métodos de análise, interpretação e indicações gerais para fins de fertilidade. Campinas, Instituto Agronômico, 29 p. (Boletim n. ${ }^{\circ} 69$ ).

CERVElliNi, A., DOS SANTOS, J. M., SAlATI, E., VIlla NOVA, N. A., REICHARDT, K., DEDICO, A., OMETTO, J. C. 1968 Análise dos dados metereológicos de Piracicaba (S.P.). Cadeira de Física e Meteorologia. ESALQ-USP. Boletim Técnico Científico n. ${ }^{\circ} 32$. Piracicaba, SP - Brasil. 
CORDOZIER, V. R. 1962 Cultivo y produción del algodón. Editorial Herrero, S. A. México, D. F.

CORRE, H. \& THIERRY, D. 1967 Essais de pulvérisatian d'azote sur les feuilles. Secteur d'expérimentation de Haute-Volta. Activité de L' J.R.C.T. Coton et fibr. trop., 23: 131-13.

COSTA, S. D., RAMOS, R. N. \& GODOY PASSOS, S. M. 1965 Cultura do algodão. Campinas, Date-Sir. $81 \mathrm{pp.} \mathrm{(mimeografado).}$

DARGAN, K. S. \& SINGH, A. 1964 Soil and foliar application of fertilizers to cotton. Indian Cott. Gr. Rev., 18: 332-335.

DEBRIGAN, P. \& THIERRY, D. 1966 Essais de pulverisation d'azote sur les feuilles. Secteur d'expérimentation de Haute-Volta. Activité de L' I.R.C.T. Coton et fibr. trop., 22: 125-126.

DURAN, D. A. 1960 Respuesta del algodoeiro a la aspersión foliar de urea Acta Agronomica. Fac. de Agron. Palmira. Univ. Nac. de Colombia. 10: $42-51$.

FRANKE, W. 1967 Mechanisms of foliar penetration of solutions. A. Rev. Pl. Physiol., 18: 281-300.

FUZATTO, M. G. 1965 XI Adubação Mineral. In. Cultura e adubação do algodoeiro. Editado pelo Instituto Brasileiro de Potassa, p. 476-508.

FUZATTO, M. G. \& FERRAZ, C. A. M. 1967 Correlação entre o efeito da adubação potássica no algodoeiro e a análise química do solo. Bragantia, 26: $345-352$.

GALIANO, L. J. 1961 Fertilización foliar con urea en el algodonero. Bol. Tecn. Serv. Invest. Prom. Agrar., 19: 1-6).

GLORIA, N. A., CATANI, R. A. \& MATUO, T. 1965 O método do EDTA na determinação de cálcio e magnésio "trocável" do solo. Revta. Agric., Piracicaba, 40: 67-74.

GRANER, E. A. 1966 Estatística. Bases para o seu emprêgo na experimentação Agronômica e em outros problemas bioiógicos. Biblioteca Agronômica Melhoramentos. São Paulo. Brasil.

HAMDI, H., DAMATY, A., BAKHATI, H. 1963 Nutrition by foliar application of cotton. Boletim 185. Beitr. Trop. Landev., in Trop. Vet. Med. Leipzig., 1. n. ${ }^{\circ}$ 1, p. 53-65 (Field Crop. Abstr., 1964, 17: 54).

HALLIDAY, D. J. 1961 Foliar application of major nutrients to fruit and plantation crops. Outl. Agric., 3: 111-115.

HUTCHINSON, J. 1962 Historia y relaciones de los algodoneros. Endeavour, 21: 5-15.

JACKSON, M. L. 1958 Soil chemical analysis. Englewod-Cliffs., N. J., Prenti ce Hall Inc., $498 \mathrm{pp}$.

JOHAM, J. E. 1951 The nutritional status of the cotton plant as indicated by tissue tests. P. Physiol., 26: 76-89.

JONES, W. F., LANCASTER, J. D., ARNOLD, B. L., HURT, B. C., MOATS, R. E., WALTON, L. 1962 Foliar applications of nitrogen to cotton. Mississipi St Univ., Agric. Exp. St., Fev., Bull. 640, 7 p.

LAGATU, H. \& MAUME, L. 1926 Diagnostic de l'alimentation d'un vegétal par l'évolution chimique d'un feuille convenablement choisie. C. R. Acad. Sci. Fr., 182: 653-655.

LANCASTE, J. D. \& SAVATLI, Z. A. 1965 Foliar application of phosphoreos for cotton. Bull. Miss. Agric. Exp. St. n. ${ }^{\circ}$ 708, p. 10.

LOTT, W. L., NERY, J. P., GALLO, R. J., MEDCALF, J. J. 1956 A técnica de análise foliar aplicada ao cafeeiro. Boletim n. 79 do Instituto Agronômico, Campinas. 
MACHADO DA SILVA, N. 1969 Estudo comparativo da adubação foliar completa do algodoeiro contra a adubação tradicional. Secção de algodão I.A.C. Bragantia (no prelo).

MACCHIAVELLO, J. N. \& ESTRADA, A. J. 1962 Ensayo de aplicación foliar de fertilizantes fosforados en sacas de algodón. Agronomia La Molina, 29 (1): 36-37.

MALAVOLTA, E. \& COURY, T. 1954 Apostila de práticas de Química Agrícola, Centro Acadêmico "Luiz de Queiroz", Piracicaba, S.P. Brasil.

MATHUR, B. N., AGRAWAL, N. K. \& SINGH, V. S. 1968 Effect of soil versus foliar applications of urea on the yield of american cotton variety "320F". The Indian J. Agric. Sci., 38: 811-815.

MELLO, F. A. F. 1958 Contribuição ao estucio da aplicação do método da diagnose foliar ao algodoeiro. Tese mimeografada. ESALQ. Piracicaba, S.P. Brasil.

MELLO, F. A. F., BRASIL SOBR. ${ }^{\circ}$, M. O. C., HAAG, H. P., ARZOLLA, S. 1960 A diagnose foliar do algodoeiro (Gassypium hirsutum, L., var. IAC 817) no Brasil. Agros, 43: 233-239.

NEPTUNE, A. M. L., CROCOMO, O. J., PIMENTEL GOMES, F., CAMPOS, H. 1961 Pulverização foliar em cafeeiro (Coffea arabica, L.) II - Aplicação de adubos potássicos. Anais Esc. Sup. Agric. "Luiz de Queiroz", 28: 277-286.

ORTOLANI, A. A. \& SILVA, M. N. 1965 VI Clima das zonas algodoeiras do Brasil. In cultura e adubação do algodoeiro. Editado pelo Instituto Brasileiro de Potassa, p. 235-253.

PAGE, A. L., BIGHAM, F. T., GANJE, T. J. \& GARBER, M. J. 1963 Availability and fixation of added potassium in two California soils when cropped to cotton. Soil Sci. Soc. Am. Proc., 27: 323-326.

PIMENTEL GOMES, F. 1963 Curso de Estatística Experimental. 2. edição. Universidade de S. Paulo, ESALQ, Piracicaba, S.P. Brasil.

PREVOT, P. \& OLLAGNIER, M. 1956 Methode D'utilisation du diagnostic foliaire, Analyse des Plantes et Problems des Fumures Minérales. Institui de Recharches pour les Huiles et Oleagineaux, Poris.

RANZANI, G., FREIRE, O. \& KINJO, T. 1966 Carta de solos do município de Piracicaba. Centro de Estudos de Solos. ESALQ-USP, Piracicaba, Brasil, 82 pp. (mimeog.).

SEMENT, G. 1967 Pulvérisation d'unée sur les feuille, Section D'Agronomie génerale. Station de Kogoni. Activité de L' J. R. C. T. Coton et Fibr. Trop., 22: 75.

SNEDECOR, W. G. 1948 Métodos de estatística, su aplicación a experimentos en agricultura y biologia. Acm e Agengy, Soc. Resp. Ltda. Buenos Aires: p. $367-428$.

TOOMEY, W. C. 1967 The Troubleshooter Cotton. Meister Publishing Cia. Willaugh, Ohio, 3: 28.

WITTIWER, S. H. 1964 Foliar absorption of plant nutrients. Adv Fron. pl. Sci., 8: 161-182.

VANNI, J. S. 1969 Agropecuaria incrementa suas vendas ao exterior. Caderno Agropecuária, Fôlha de São Paulo. $10^{\circ}$ de nov. n. 14748.

VERDADE, F. DA C., PIMENTEL, W. A. C., AMARAL, DO Z. A., IGUE, K. \& CAVALERI, P. A. 1965 Níveis de fertilidade dos solos de Estrado de São Paulo para a cultura algodoeira. I - Os teores de fósforo, nitrogênio e potássio. Bragantia, 24 (6): 55-74.

VERNA, S. S. \& SAHNNI, V. M. 1963 Effect of foliar application of nutrients on the yield of cotton. Indian Cott. Gr. Rev., 17: 247-248 